\title{
GPPS-BJ-2019-0021
}

\section{EFFECT OF THE FENCE HEIGHT ON THE LEAKAGE FLOW CHARACTERISTICS OF BRUSH SEALS}

\author{
Yuanqiao ZHANG, Dengqian MA \\ Institute of Turbomachinery, Xi'an Jiaotong \\ University \\ Xi'an, China
}

\author{
Jun LI* \\ Institute of Turbomachinery, Xi'an Jiaotong \\ University \\ junli@mail.xjtu.edu.cn \\ Xi'an, China
}

\author{
Yuan HE, Jingjin JI, Bo SUN \\ Shanghai Electric Gas Turbine Co. Ltd. \\ Shanghai, China
}

\author{
Zhigang LI, Xin YAN \\ Institute of Turbomachinery, Xi'an Jiaotong University \\ Xi'an, China
}

\begin{abstract}
Effect of the fence height on the leakage flow characteristics of brush seals is investigated by means of experimental measurements and numerical simulations. The leakage flow rate of brush seal with three sizes of fence height is measured at six rotor surface velocities ranged from $0 \mathrm{~m} / \mathrm{s}$ to $62.8 \mathrm{~m} / \mathrm{s}$ among pressure differences $9.64 \mathrm{kPa}$ to $192.8 \mathrm{kPa}$ and the working fluid is air. The detailed leakage flow field of the experimental brush seals is numerically analyzed using threedimensional Reynolds-Averaged Navier-Stokes (RANS) and SST turbulence model based on the Non-Darcian porous medium. The accuracy of the numerical method is validated by comparison of experimental data. The obtained results show that the effective clearance of brush seal decreases with the fence height decreases at the fixed rotor surface velocity and pressure difference. The effective clearance of brush seal with three sizes fence height increases significantly with the increases of pressure differences at the fixed rotor surface velocity. The effective clearance of interference brush seals slightly decrease with the increasing rotor surface velocity due to the friction heat generation. Effect of the rotor surface velocity on the effective clearance of brush seal is limited when the bristles wear and friction heat generation is not considered. The detailed leakage flow field of the brush seal is also illustrated.
\end{abstract}

\section{INTRODUCTION}

The leakage rate of brush seal is only $10 \%-20 \%$ of that of the traditional labyrinth seal. Flexible bristles have strong adaptability to the eccentric operation of the rotor. Therefore, brush seals are widely used in turbomachinery (Aslan-zada, 2012; Schur, 2018 ).
The research on leakage flow characteristics of brush seals mainly focuses on experimental measurement and numerical analysis. Carlile et al. (1993) measured the leakage rate of brush seals for three different working fluids including helium, air and carbon dioxide at low and zero rotor surface velocities. The results show that the leakage flow rate of brush seals decreases slightly at low rotating speeds compared with zero rotor surface velocity. Li et al. (2012) analyzed effect of clearance sizes on the leakage performance of a labyrinthbrush seal and found that the blow-down effect should be considered for clearance brush seals. Hildebrandt et al. (2019) experimentally investigated the effect of bristle pack density, rotor-bristle interference, rotational speed and pressure difference on leakage flow of a kind of clamped brush seal with an axially inclined bristles pack.

At present, the numerical study of leakage flow behaviors of brush seals is mainly based on the non-Darcian porous medium model due to the limitations of cross-flow models and bulk flow models (Dogu, 2016). Li et al. (2010) numerically studied the clearance on the leakage flow characteristics of brush seal. Dogu and Aksit (2006) numerically investigated the influences of the front plate and backing plate geometries on leakage flow behaviors of the brush seals. Dogu et al. (2016) numerically analyzed the leakage rates of brush seals under different working conditions and different geometric conditions and found that the geometric parameters and working conditions that play decisive roles in leakage flow are bristle pack thickness, clearance between bristle pack and rotor, fence height, and pressure difference.

Considering the thermal deformation of the rotor and transient operating conditions, there should be an appropriate radial distance between the rotor and the front/backing plate of brush seals. The radial distance between the backing plate 
and rotor named as backing plate fence height is one of the key factors during the design of brush seal (Kirk, 2015). The high backing plate fence height will significantly increase the leakage flow rate. The radial distance between the front plate and rotor named as front plate fence height has little effect on leakage flow rate of brush seal (Dogu, 2016) but would affect the flow behaviour of brush seals. The information on the leakage flow characteristics of brush seals with different fence height is not significant. The purpose of this paper is to study the influence of the fence height on leakage flow characteristics of brush seals by means of experiment and numerical simulation.

\section{EXPERIMENTAL TEST RIG AND NUMERICAL METHOD}

\section{Experimental Test Rig}

Figure 1 shows the experimental test rig for brush seals. The downstream of the experimental brush seal is connected with the atmosphere. At the same time, the inlet pressure and mass flow rate of compressed air entering the seal test section are adjusted by the flow rate controlling valve. The inlet total pressure, temperature and mass flow rate are obtained by the total pressure probe, T-type thermocouple and thermal gas mass flowmeter, respectively. And the uncertainty of these three apparatus is $0.075 \%, 0.75 \%$ and $1.5 \%$, respectively. The motor is connected with the rotational shaft through a coupling, and the rotor surface velocity can be adjusted by controlling the motor through a frequency converter. More discussion of the experimental test rig is shown in the literature (Zhang, 2018).

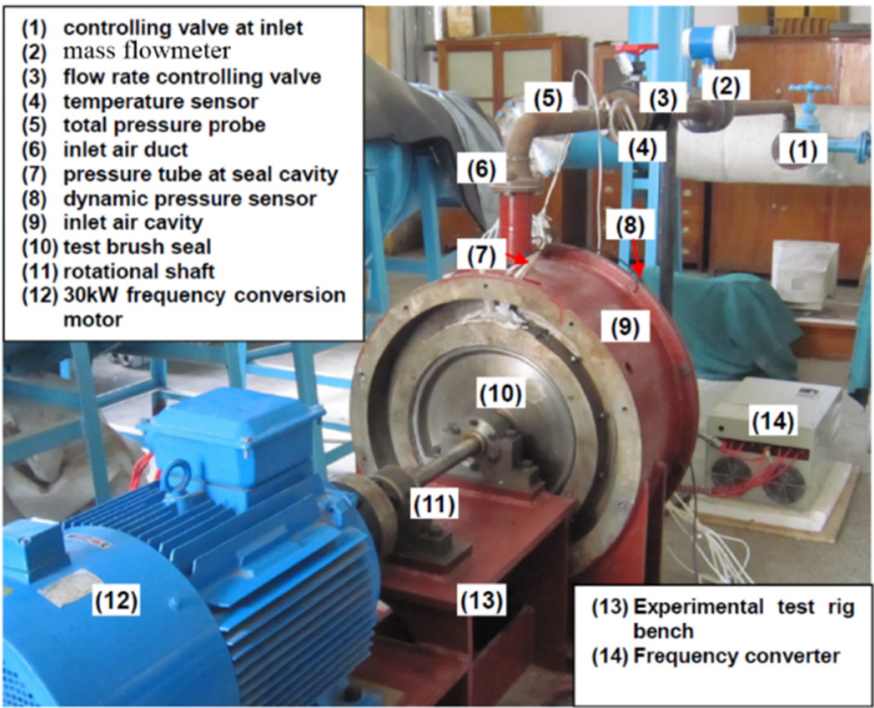

Figure 1 Experimental test rig for brush seals

At first, the effect of the fence height on the leakage flow characteristics of three brush seals was experimentally studied in this study. Figure 2 shows the three experimental brush seals with different fence heights. The bristle material is Haynes ${ }^{\circledR} 25$ (Zhang, 2018), which is widely used in brush seal. As shown in Table 1, the three brush seals have the same geometric structure except for the fence height. It should be noted that the backing plate height and front plate fence height are modified at the same time.
Table 1 Geometrical parameters of brush seals

$\begin{array}{ll}\text { Rotor diameter } D / \mathrm{mm} & 400 \\ \text { Bristle pack cold width } W / \mathrm{mm} & 2.17 \\ \text { Bristle diameter } d / \mathrm{mm} & 0.15 \\ \text { Front plate width } W_{2} / \mathrm{mm} & 3 \\ \text { Backing plate width } W_{1} / \mathrm{mm} & 3 \\ \text { Axial size of groove } W_{3} / \mathrm{mm} & 0.83 \\ \text { Bristle lay angle } \alpha /{ }^{\circ} & 45 \\ \text { Fence height } H / \mathrm{mm} & 2.55 / 3.55 / 4.55 \\ \text { Bristle pack height } H_{b} / \mathrm{mm} & 15.25\end{array}$

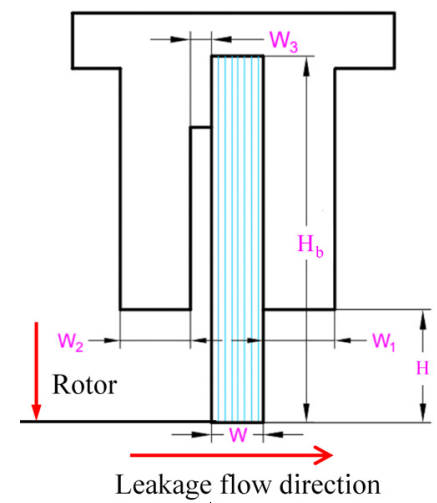

(a) cross-section diagram ( $\mathrm{H}=2.55 / 3.55 / 4.55 \mathrm{~mm}$ )

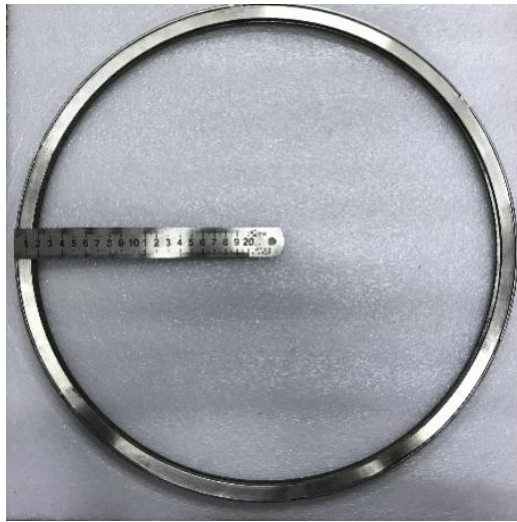

(b) physical photograph of configuration 2

Figure 2 Experimental brush seals

\section{Numerical Method}

As shown in Eq. (1), the porous medium model is used to study the flow behaviors within bristle pack in this work, which means that the resistance of the bristle to the fluid is added to the momentum equation as a source term in the bristle pack region. More information about the porous medium model can be found in the previous work ( $\mathrm{Li}, 2012$; Zhang, 2018; Qiu and Li, 2013; Qiu, 2014).

$$
\frac{\partial\left(\rho \mathrm{u}_{j} \mathrm{u}_{i}\right)}{\partial x_{j}}=-\frac{\partial p}{\partial x_{i}}+\frac{\partial \sigma_{i j}}{\partial x_{j}}+F_{b i}
$$

A $1^{\circ}$ slice section CFD model is used to investigate the leakage flow in brush seal because the structure and flow of the brush seal are periodic in the circumferential direction. As shown in Figure 3, the boundary layer grids of the computational model are refined, and the three brush seals 
grids have about $9.85 \times 10^{5}$ nodes, which satisfies the requirements of grid independence and SST turbulence model for yplus. The working medium is an ideal gas. Table 2 shows a total of boundary conditions. The pressure differences ranges from $9.64 \mathrm{kPa}$ to $192.8 \mathrm{kPa}$ with an interval of 19.28 $\mathrm{kPa}$.

\section{Table 2 Boundary conditions}

$\begin{array}{lll}\text { Inlet total temperature } & T_{\text {in,tot }} /{ }^{\circ} \mathrm{C} & 34 \\ \text { Pressure differences } \Delta P \quad / \mathrm{kPa} & 9.64 \sim 192.8 \\ \text { Outlet static pressure } & p_{\text {out }} / \mathrm{kPa} & 96.4 \\ \text { Rotor surface velocity } & v_{R} / \mathrm{m} / \mathrm{s} & 0 / 62.8\end{array}$

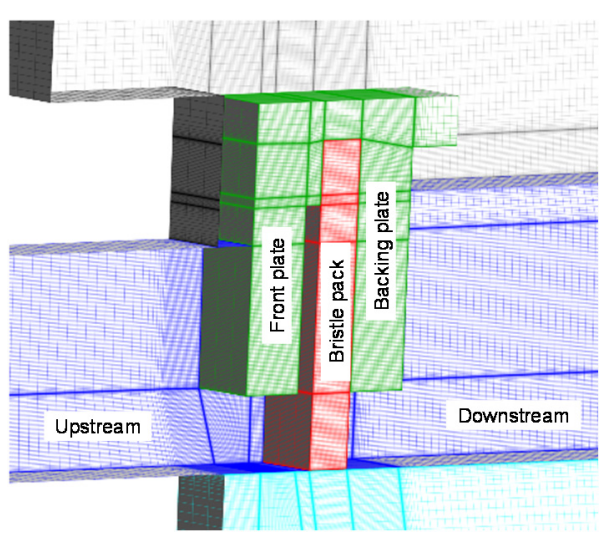

\section{Figure 3 Computational grid of configuration 2 brush seal}

\section{RESULTS AND DISCUSSIONS}

The leakage flow rate of the brush seals with three kinds of fence heights is experimentally measured at six rotor surface velocities ranged from $0 \mathrm{~m} / \mathrm{s}$ to $62.8 \mathrm{~m} / \mathrm{s}$ within difference pressures $9.64 \mathrm{kPa}$ to $192.8 \mathrm{kPa}$. The detailed leakage flow pattern of the experimental brush seals is numerically conducted using 3D RANS coupled Non-Darcian Porous medium model solutions. Effect of the fence heights on the leakage flow characteristics of brush seals is discussed.

\section{Leakage Flow Performance}

Leakage data are expressed by the effective clearance (Pugachev, 2014) as $h_{\text {eff }}$ shown in Equation (2). As shown in Figure 4, the effective clearance of three brush seals increases first and then decreases with the increase of the rotor surface velocity at the fixed pressure difference.

$$
\begin{aligned}
& h_{\text {eff }}=\dot{m} \cdot \sqrt{T_{\text {in,tot }}} /\left(\pi \cdot D \cdot p_{\text {in }, \text { tot }} \cdot Q\right) \\
& Q= \begin{cases}\sqrt{\frac{2 \gamma}{R_{s}(\gamma-1)}\left[\left(\frac{p_{\text {out }}}{p_{\text {in,tot }}}\right)^{\frac{2}{\gamma}}-\left(\frac{p_{\text {out }}}{p_{\text {in }, \text { tot }}}\right)^{\frac{\gamma+1}{\gamma}}\right]}, \text { if } \frac{p_{\text {in,tot }}}{p_{\text {out }}} \leq\left(\frac{\gamma+1}{2}\right)^{\frac{\gamma}{\gamma-1}} \\
\sqrt{\frac{\gamma}{R_{s}}\left(\frac{2}{\gamma+1}\right)^{\frac{\gamma+1}{\gamma-1}}}, & \text { otherwise }\end{cases}
\end{aligned}
$$

where $T_{i n, t o t}$ is inlet total temperature, $\gamma$ and $R_{s}$ are constants and their value is 1.4 and $287.04 \mathrm{~J} / \mathrm{kg} / \mathrm{K}$, respectively. $\dot{m}$ is leakage flow rate, $p_{\text {out }}$ and $p_{\text {in,tot }}$ are the outlet static pressure and inlet total pressure, respectively, and $D$ denotes the rotor diameter.

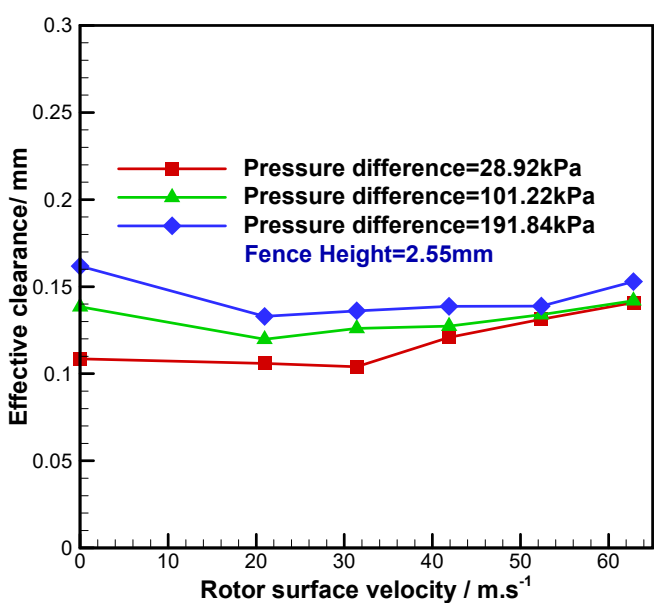

(a) configuration 1

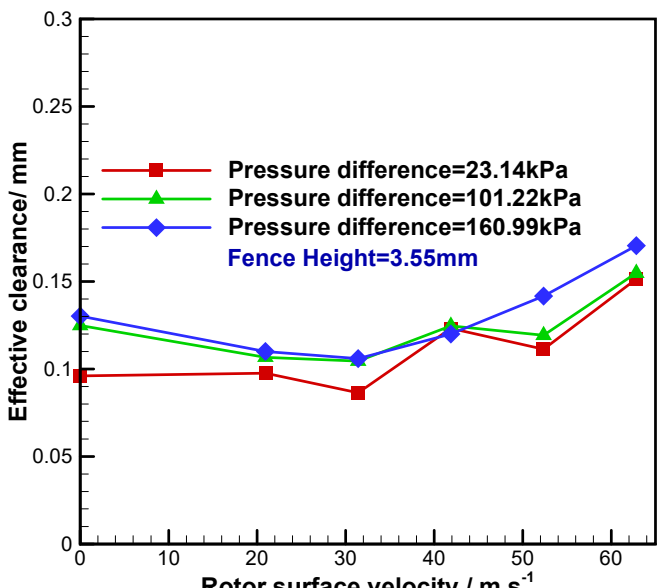

(b) configuration 2

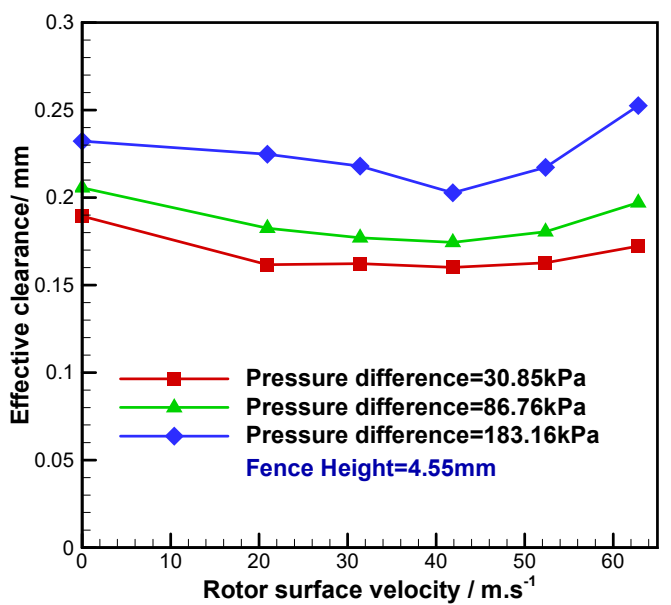

(c) configuration 3

Figure 4 Variation of the effective clearance of three brush seals with rotor surface velocity 


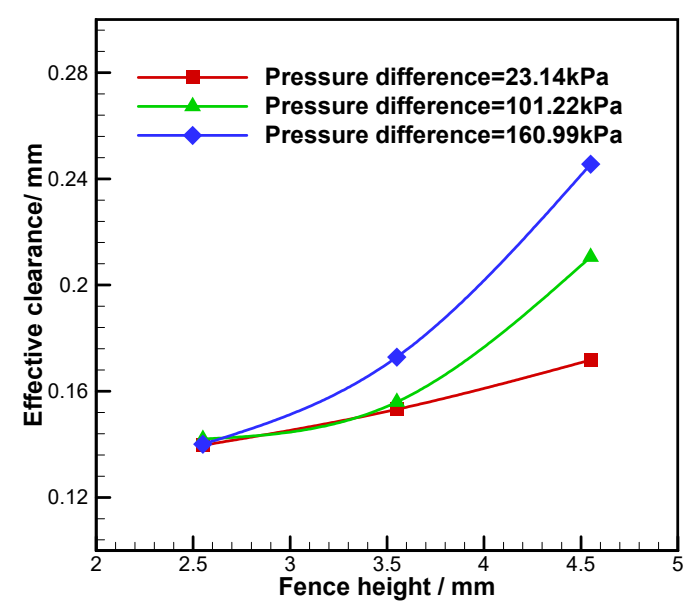

Figure 5 The relationship between the effective clearance and fence height at different pressure differences $\left(v_{R}=62.8 \mathrm{~m} / \mathrm{s}\right)$

It should be noted that the effective clearance of brush seals under different pressure differences was first measured at a fixed rotor surface velocity. Then the rotor speed is set to another speed and repeat the above steps until the change of effective clearance with pressure differences at the rotor surface velocity of $62.8 \mathrm{~m} / \mathrm{s}$ is obtained. In other words, the data plotted in Figure 4 and Figure 5 are not obtained by fixing the pressure difference to a certain value and then changing the rotor surface velocity. The wear of bristles is not obvious at low rotor surface velocity condition, and the frictional heat generation between rotor and bristle pack will increase the temperature of air, so the air density and effective clearance slightly decreases with the increasing rotor surface velocity (Qiu, 2015). Besides, the enhancement of viscous dissipation leads to a slight reduction of effective clearance at low rotor surface velocity condition (Qiu, 2014). While the effective clearance increases at high rotor surface velocity due to the bristles wear during the experiment.

As illustrated in Figure 5, the effective clearance of brush seals increase rapidly with the increasing fence height, especially at high pressure difference conditions. The effective clearance of configuration 3 brush seal is increased by approximately $75 \%$ compared with that of configuration 1 brush seal at a pressure difference of $155.2 \mathrm{kPa}$. So the fence height should be designed to be as small as possible, from the perspective of reducing leakage. It should be noted that the fence height is determined by the radial vibration amplitude of the rotor considering that backing plate and front plate should not be in contact with the rotor due to the rotor transient vibration (Dogu, 2016; Kirk, 2015).

\section{Leakage Flow Pattern}

Figure 6 shows the experimentally measured and numerical calculated effective clearance of versus pressure difference for three brush seals. Though there is an error between the calculated and experimental values of effective clearance for low pressure difference conditions, the calculated results agree with the experimental results basically, which verifies the effectiveness of the CFD model. The effective clearance decreases rapidly with the decreasing fence height, and the reduction is very obvious at the high pressure difference condition. In addition, compared with the other two configurations, the effective clearance of configuration 3 is more sensitive to pressure difference in the range of experimental pressure differences. It may be due to the fact that change of the effective clearance of configuration 1 and configuration 2 seals with pressure difference is not fully presented, considering the low experimental pressure and the low leakage flow of configuration 2 and configuration 1 seals. The effect of the rotor surface velocity on the effective clearance of brush seal is limited. It should be noted that the friction generated by the friction between the rotor and the bristle pack is small after the bristles are worn, and they can be considered as line-to-line brush seals, so the influence of frictional heat generation on the leakage flow characteristics is not considered.

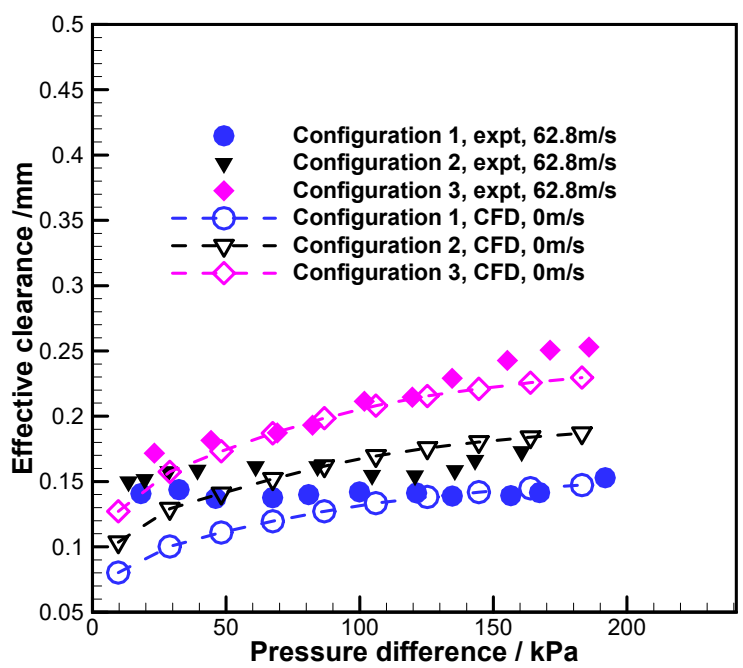

(a) CFD results of $v_{R}=0 \mathrm{~m} / \mathrm{s}$

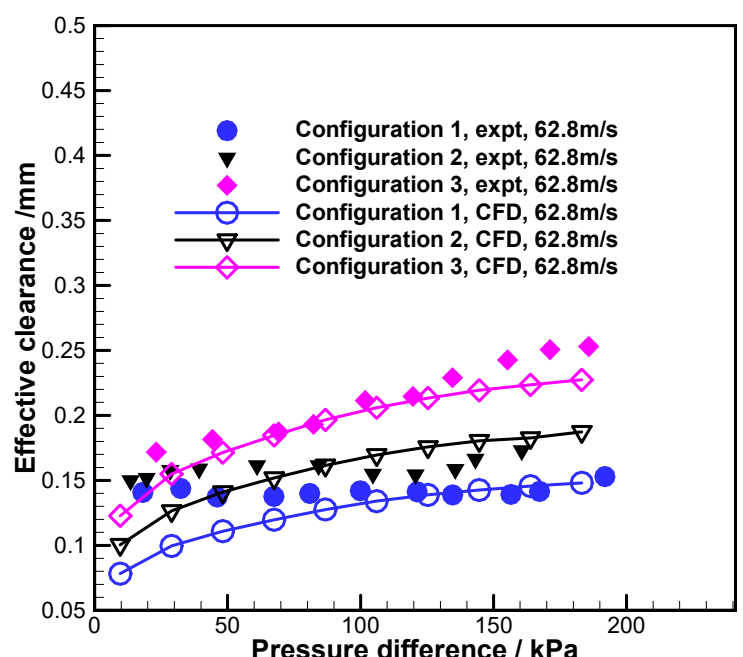

(b) CFD results of $v_{R}=62.8 \mathrm{~m} / \mathrm{s}$

\section{Figure 6 Comparison between numerical results and experimental effective clearance}

Figure 7 and Figure 8 show the static pressure contours and the streamlines distribution of three brush seals at a rotor surface velocity of zero and a rotor surface velocity of $62.8 \mathrm{~m} / \mathrm{s}$, respectively. It can be seen that the area around the fence height bears most of the pressure drop due to the flow 
resistance of the bristle pack and the obstruction of backing plate. The fence height and rotor surface velocity have significant impacts on the streamlines distribution of brush seals.

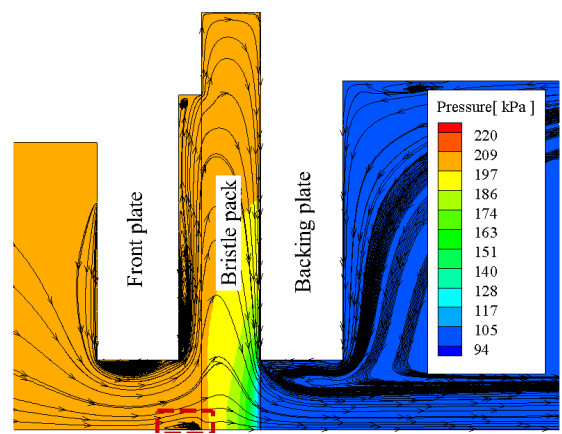

(a) configuration 1

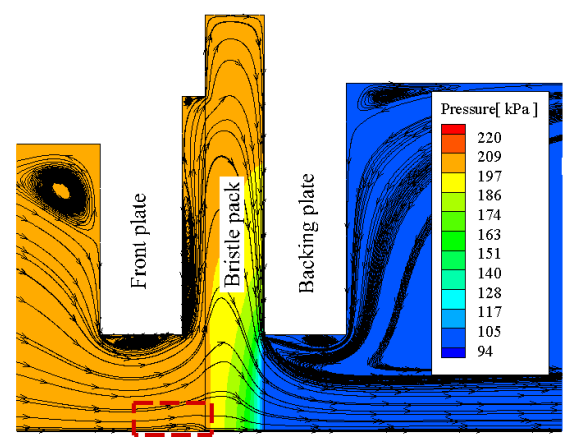

(b) configuration 2

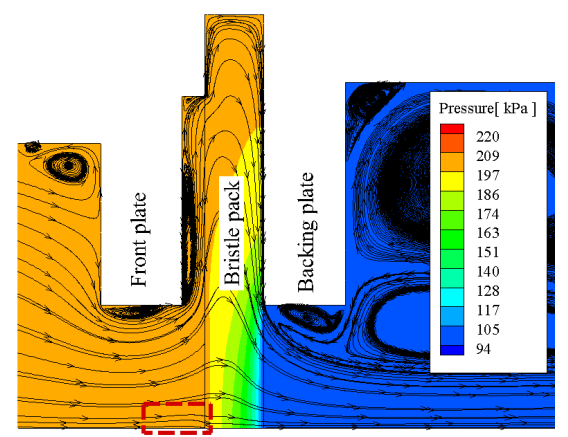

(c) configuration 3

Figure 7 Static pressure contours and streamline distribution of three brush seals ( $\triangle P=106.04 \mathrm{kPa}$, $v_{R}=0 \mathrm{~m} / \mathbf{s}$ )

As the fence height increases, the bristle pack in more region is directly connected to the downstream in the absence of isolation of the backing plate, which leads to the decrease of the static pressure of the bristles pack. The shapes, sizes, and number of vortices in the flow field vary significantly with the increase of fence height. As shown in Figure 7, when the rotor surface velocity is zero, the vortex in the red dotted box region disappear and the vortex below the backing plate increase as fence height increases. Comparing the streamlines of the red dotted box region in Figures 7 and 8 , The phenomenon that upstream streamlines of the bristle pack near the rotor move upward with the increase of the rotor surface velocity can be found, so the flow path of airflow in the bristle pack increases and the effective clearance decreases. When rotor surface velocity increases, the vortex in the red dotted box region of configuration 1 brush seal increases and a vortex appears in the red dotted box region of configuration 2 brush seal and configuration 3 brush seal.

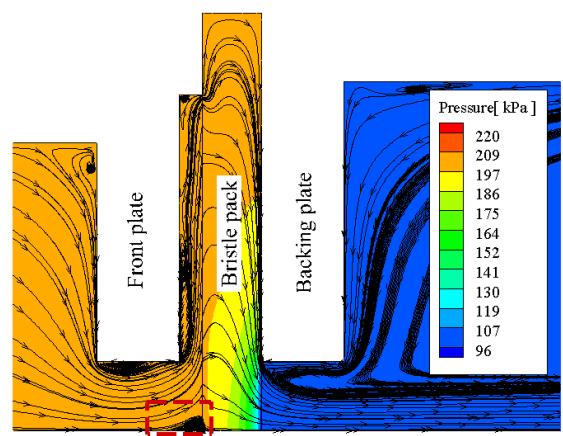

(a) configuration 1

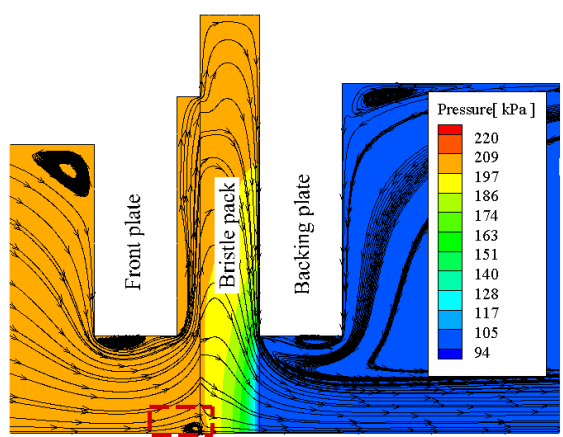

(b) configuration 2

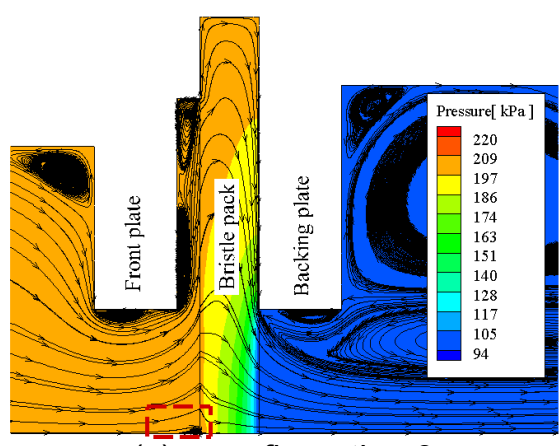

(c) configuration 3

Figure 8 Static pressure contours and streamline distribution of three brush seals $(\Delta P=106.04 \mathrm{kPa}$, $v_{R}=62.8 \mathrm{~m} / \mathrm{s}$ )

Figures 9 - 11 show the static pressure contours and streamlines distribution of three brush seals at different pressure differences and fixed rotor surface velocity of $0 \mathrm{~m} / \mathrm{s}$. As to the configuration 1 , the effect of the pressure difference on the streamline distribution in the bristle pack is limited. The leakage flow impacts onto the bristle pack and permeates across the bristle pack. In addition, the leakage flow in the bristle pack downwards to the shaft surface along the radial direction due to the action of the pressure difference. The pressure drop mostly located across the bristle pack is observed. The effect of the pressure difference on the leakage flow pattern of the configuration 2 and 3 is similar to configuration 1 . 


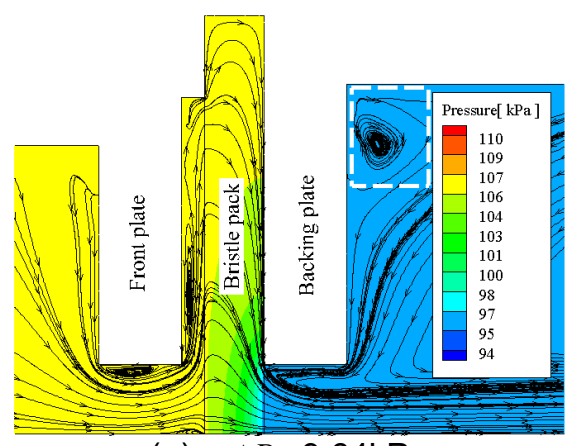

(a) $\Delta P=9.64 \mathrm{kPa}$

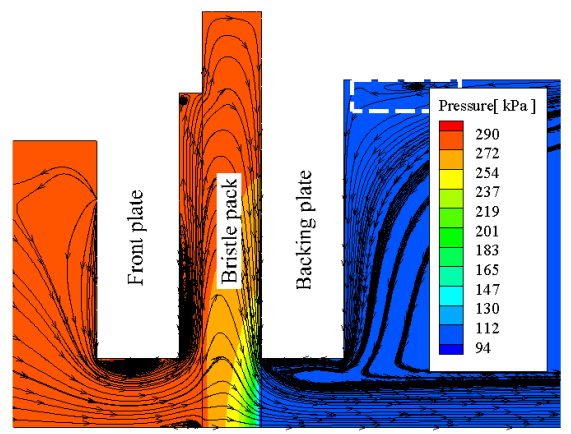

(b) $\Delta P=183.16 \mathrm{kPa}$

Figure 9 Static pressure contours and streamline distribution of configuration 1 brush seal $\left(v_{R}=0 \mathrm{~m} / \mathrm{s}\right)$

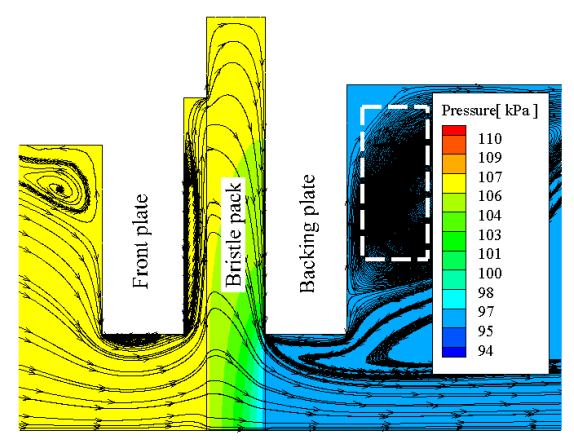

(a) $\Delta P=9.64 \mathrm{kPa}$

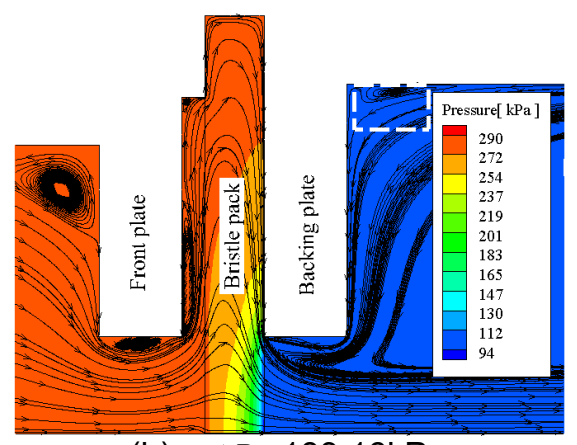

(b) $\Delta P=183.16 \mathrm{kPa}$

Figure 10 Static pressure contours and streamline distribution of configuration 2 brush seal $\left(v_{R}=0 \mathrm{~m} / \mathrm{s}\right)$

The effect of the fence height on the leakage flow pattern of the brush seals is captured as show in Figures 9-11. As to brush seal configuration 1 and 2 , the size of the vortices in the white dotted box region decrease significantly when pressure difference increases. The size of the vortex in the groove between front plate and bristle pack of configuration 2 also decreases with the increasing pressure difference. The fence height of the brush seal configuration 1 and 2 equals $2.55 \mathrm{~mm}$ and $3.55 \mathrm{~mm}$. For brush seal of configuration 3 , the fence height increases to $4.55 \mathrm{~mm}$, the size of vortices in the white dotted box region increase with the increasing pressure difference. The larger fence height increases the regions of the leakage flow across the bristle packs of the brush seal. The fence height changes the leakage flow pattern and corresponding the leakage flow rate across the brush seal.

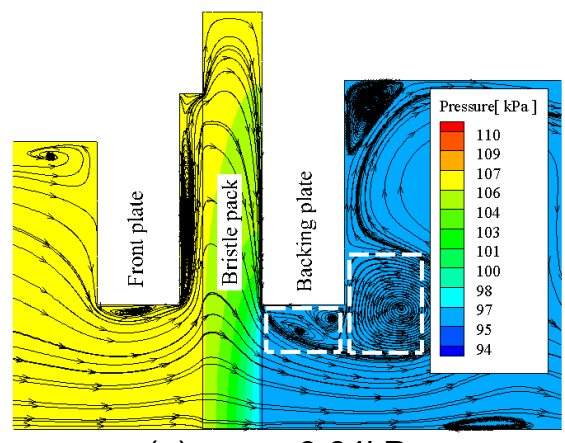

(a) $\Delta P=9.64 \mathrm{kPa}$

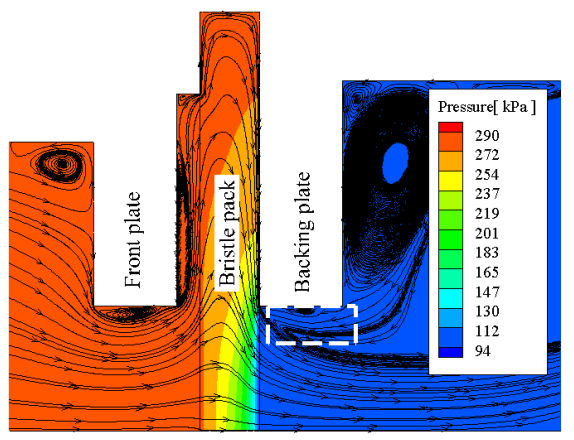

(b) $\Delta P=183.16 \mathrm{kPa}$

Figure 11 Static pressure contours and streamline distribution of configuration 3 brush seal at different pressure differences $\left(v_{R}=0 \mathrm{~m} / \mathrm{s}\right)$

\section{CONCLUSIONS}

Effect of the fence height on the leakage flow characteristics of brush seals was investigated based on the experimental measurement and numerical method using the non-Darcian porous medium model. The accuracy of the numerical method is validated by comparison of experimental data. The following conclusions were reached.

The effective clearance of the brush seal increases significantly with the increasing fence height at the fixed rotor surface velocity and pressure difference. The effective clearance of brush seals with three sizes fence height increases significantly due to the increasing pressure difference at the fixed rotor surface velocity.

The effective clearance of interference brush seals slightly decrease with the increasing rotor surface velocity due to the friction heat generation between rotor and bristle pack increase with the increase of the rotor surface velocity when the bristles wear is not considered or not obvious. While the effect of the rotor surface velocity on the effective clearance of brush seals is limited as the bristles wear and friction heat generation is not considered. 
The bristle pack around the fence height bears most of the pressure drop. As the fence height increases, the static pressure inside the bristle pack decreases. The upstream streamline of the bristle pack near the shaft moves upward due to the increase of rotor surface velocity.

\section{NOMENCLATURE}

$d \quad$ bristle diameter [mm]

$D \quad$ rotor diameter $[\mathrm{mm}]$

$F_{b i} \quad$ additional resistance term $\left[\mathrm{N} / \mathrm{m}^{3}\right]$

$h_{\text {eff }} \quad$ effective clearance of the brush seal

$[\mathrm{mm}]$

$H$ fence height [mm]

$H_{b} \quad$ bristle pack height $\quad[\mathrm{mm}]$

$\dot{m} \quad$ leakage flow rate of the brush seal $[\mathrm{kg} / \mathrm{s}]$

$p_{\text {in,tot }} \quad$ inlet total pressure $\quad[\mathrm{kPa}]$

$p_{\text {out }} \quad$ outlet static pressure $\quad[\mathrm{kPa}]$

$Q \quad$ flow function $\quad\left[\mathrm{s} . \mathrm{K}^{0.5} / \mathrm{m}\right]$

$T_{\text {in,tot }} \quad$ inlet total temperature $\quad[\mathrm{K}]$

$u \quad$ velocity $[\mathrm{m} / \mathrm{s}]$

$v_{R} \quad$ rotor surface velocity $[\mathrm{m} / \mathrm{s}]$

$W \quad$ bristle pack width $\quad[\mathrm{mm}]$

$W_{1} \quad$ backing plate width [mm]

$W_{2} \quad$ front plate width [mm]

$W_{3} \quad$ axial size of groove $\quad[\mathrm{mm}]$

$\Delta P \quad$ Pressure difference $\quad[\mathrm{kPa}]$

$\alpha \quad$ bristle lay angle $\left[{ }^{\circ}\right]$

$\rho$ density $\left[\mathrm{kg} / \mathrm{m}^{3}\right]$

$\sigma \quad$ Reynolds stress $\left[\mathrm{N} / \mathrm{m}^{2}\right]$

\section{ACKNOWLEDGEMENT}

This study has been funded by the National Key R\&D Program of China (2017YFB0601804) and the National Natural Science Foundation of China (Grant No.51776152).

\section{References}

Aslan-zada F. E., Mammadov V. A., and Dohnal F. (2012). Brush seals and labyrinth seals in gas turbine applications. Proceedings of the Institution of Mechanical Engineers Part A-Journal of Power and Energy. 227(2): 216-230. http://dx.doi.org/10.1177/0957650912464922.

Schur F., Friedrichs J., Flegler J., Georgakis C., and Polklas T. (2018). Pressure Distributions Below Brush Seals at Varying Operating Conditions. Proceedings of ASME Turbo Expo 2018: GT2018-76194. http://dx.doi.org/10.1115/GT201876194.

Carlile J. A., Hendricks R. C., and Yoder D. A. (1993). Brush Seal Leakage Performance with Gaseous Working Fluids at Static and Low Rotor Speed Conditions. Journal of Engineering for Gas Turbines and Power. 115(2): 397-403. http://dx.doi.org/10.1115/1.2906722.

Li J., Qiu B., and Feng Z. (2012). Experimental and Numerical Investigations on the Leakage Flow Characteristics of the Labyrinth Brush Seal. Journal of Engineering for Gas
Turbines and Power. 134(10): 102509-1-9. http://dx.doi.org/10.1115/1.4007062.

Hildebrandt M., Schwitzke C., and Bauer H. (2019). Experimental Investigation on the Influence of Geometrical Parameters on the Frictional Heat Input and Leakage Performance of Brush Seals. Journal of Engineering for Gas Turbines and Power. 141(4): 042504-1-10. http://dx.doi.org/10.1115/1.4038767.

Dogu Y., Bahar A. S., Sertçakan M. C., Pişkin A., Arıcan E., et al. (2016). Computational Fluid Dynamics Investigation of Brush Seal Leakage Performance Depending on Geometric Dimensions and Operating Conditions. Journal of Engineering for Gas Turbines and Power. 138(3): 032506-1-13. http://dx.doi.org/10.1115/1.4031370.

Li J., Huang Y., and Li Z. (2010). Effects of Clearances on the Leakage Flow Characteristics of Two Kinds of Brush Seals and Referenced Labyrinth Seal. Proceedings of ASME Turbo Expo 2010: GT2010-22877. http://dx.doi.org/10.1115/GT2010-22877.

Dogu Y., and Aksit M. F. (2006). Effects of geometry on brush seal pressure and flow fields - Part I: Front plate configurations. Journal of Turbomachinery. 128(2): 367-378. http://dx.doi.org/10.1115/1.2101857.

Dogu Y., and Aksit M. F. (2006). Effects of geometry on brush seal pressure and flow fields - Part II: Backing plate configurations. Journal of Turbomachinery. 128(2): 379-389. http://dx.doi.org/10.1115/1.2101858.

Kirk T., Bowsher A., Crudgington P., and Chupp R. (2015) Aspects of Brush Seal Design. 51st AIAA/SAE/ASEE Joint Propulsion Conference: AIAA 2015-4230. https://doi.org/10.2514/6.2015-4230.

Dogu Y., Bahar A. S., Sertçakan M. C., Pişkin A., Arıcan E., and Kocagül M. (2016). Computational Fluid Dynamics Investigation of Brush Seal Leakage Performance Depending on Geometric Dimensions and Operating Conditions. Journal of Engineering for Gas Turbines and Power, 2016, 138 (3): 032506-1-13. http://dx.doi.org/10.1115/1.4031370.

Zhang Y., Li J., Yan X., and Li Z. (2018). Experimental and Numerical Investigations on Leakage Flow Characteristics of Two Kinds of Brush Seals. Proceedings of ASME Turbo Expo 2018: GT2018-76235. http://dx.doi.org/10.1115/GT201876235 .

Qiu B., Li J., and Yan X. (2014). Investigation into the flow behaviour of multi-stage brush seals. Proceedings of the Institution of Mechanical Engineers Part A: Journal of Power $\begin{array}{lll}\text { and } \quad \text { Energy. } & \text { 228(4): }\end{array}$ http://dx.doi.org/10.1177/0957650914522456.

Qiu B., and Li J. (2013). Numerical Investigations on the Heat Transfer Behaviour of Brush Seals Using Combined Computational Fluid Dynamics and Finite Element Method. 
Journal of Heat Transfer. 135(12): 122601-1-10. http://dx.doi.org/10.1115/1.4024556.

Pugachev A. O. (2014). Aggregation of Experimental and Theoretical Data for Brush Seal Leakage Evaluation. 50th AIAA/ASME/SAE/ASEE Joint Propulsion Conference: AIAA 2014-3598. http://dx.doi.org/10.2514/6.2014-3598.

Qiu B., Li J., and Feng Z. (2015). Investigation of Conjugate Heat Transfer in Brush Seals using Porous Media Approach under Local Thermal Non-Equilibrium Conditions. Proceedings of ASME Turbo Expo 2015: GT2015-42550. http://dx.doi.org/10.1115/GT2015-42550. 